\title{
Chain elongation in anaerobic reactor microbiomes to recover resources from waste
}

\author{
Catherine M Spirito ${ }^{1}$, Hanno Richter ${ }^{1}$, Korneel Rabaey ${ }^{2}$, \\ Alfons JM Stams ${ }^{3,4}$ and Largus T Angenent ${ }^{1}$
}

\begin{abstract}
Different microbial pathways can elongate the carbon chains of molecules in open cultures of microbial populations (i.e. reactor microbiomes) under anaerobic conditions. Here, we discuss three such pathways: 1 . homoacetogenesis to combine two carbon dioxide molecules into acetate; 2 . succinate formation to elongate glycerol with one carbon from carbon dioxide; and 3. reverse $\beta$ oxidation to elongate short-chain carboxylates with two carbons into medium-chain carboxylates, leading to more energy-dense and insoluble products (e.g. easier to separate from solution). The ability to use reactor microbiomes to treat complex substrates can simultaneously address two pressing issues: 1 . providing proper waste management; and 2. producing renewable chemicals and fuels.
\end{abstract}

\begin{abstract}
Addresses
${ }^{1}$ Department of Biological and Environmental Engineering, Cornell University, 226 Riley-Robb Hall, Ithaca, NY 14853, USA

${ }^{2}$ Laboratory of Microbial Ecology and Technology, Faculty of Bioscience Engineering, Ghent University, Coupure Links 653, 9000 Ghent, Belgium ${ }^{3}$ Laboratory of Microbiology, Wageningen University, Dreijenplein 10, 6703 HB Wageningen, The Netherlands

${ }^{4}$ Centre of Biological Engineering, University of Minho, Campus de Gualtar, 4710-057 Braga, Portugal
\end{abstract}

Corresponding author: Angenent, Largus T (la249@cornell.edu)

Current Opinion in Biotechnology 2014, 27:115-122

This review comes from a themed issue on Energy biotechnology

Edited by Arthur J Ragauskas and Korneel Rabaey

0958-1669/\$ - see front matter, (C) 2014 Elsevier Ltd. All rights reserved. http://dx.doi.org/10.1016/j.copbio.2014.01.003

\section{Introduction}

Open cultures of anaerobic microbial populations break down and convert waste organic materials into a mixture of mainly short-chain carboxylic acids with 2-4 carbon atoms [C2-C4]), carbon dioxide, and hydrogen [1]. We refer to these open cultures as anaerobic reactor microbiomes, not only because they have a lot in common with gut microbiomes, but also because this terminology innately infers to open cultures instead of artificially mixed communities of once pure cultures. Carboxylic acids are weak organic acids with at least one carboxyl group and throughout the text we will refer to them as carboxylates to include both the undissociated and dissociated species (e.g. acetic acid is acetate, lactic acid is lactate, and succinic acid is succinate). The short-chain carboxylates can accumulate or be converted further to, for example, methane by acetogens and methanogens within the same anaerobic reactor microbiome. This conversion into methane occurs within a well-operated anaerobic digestion system. However, methane is a low value product that may subside anaerobic digestion into an economically unattractive technology when governmental subsidies or policies are absent [2]. Fortunately, other fermentation products with a higher monetary value can be produced from wastes under anaerobic conditions. Moreover, the carbon chains of the carboxylates can be elongated within the same anaerobic reactor microbiome when reduced compounds are present $\left[3^{\circ}\right]$. Here, we review promising chain-elongation pathways.

We have limited the scope of this review, however, to pathways that have been described when enriched within anaerobic reactor microbiomes because of the following advantages compared to pure or defined-mixed cultures in bioprocesses: 1 . the avoidance of sterilization and antibiotic additions; 2 . the adeptness to treat complex and variable organic waste substrates [1]; 3. the circumvention of using pure cultures as an inoculum; 4. the prospect to enrich for uncultured isolates with advanced functions from an undefined inoculum; and 5. the ability to operate bioprocesses in a (semi)-continuous mode for many years. These advantages make conversion of waste economically feasible, and thus we focus here on microbial systems that do not compete with human food production. Previously noted disadvantages for reactor microbiomes, such as instability and unpredictability, were not observed for methanogenic microbiomes in well-operated anaerobic digestion systems. In fact, these reactor microbiomes were stable and resilient $\left[4^{\bullet}, 5\right]$, which has resulted in efficient performance during many years of operation for thousands of full-scale anaerobic digesters worldwide [6]. In the first section of this review, we focus on relevant microbial pathways that are known to elongate carbon chains in reactor microbiomes without the addition of external electron acceptors (visualized in Figure $1 \mathrm{a}-\mathrm{c}$ ) - each sub-section reviews one of three microbial pathways (sub-section headings a-c). In the second section of this review, we focus on technologies that may be necessary to aid chain elongation.

\section{Pathways}

\section{Homoacetogenesis (a)}

Homoacetogens utilize the Wood-Ljungdahl (reductive acetyl-CoA) pathway under anaerobic conditions to 


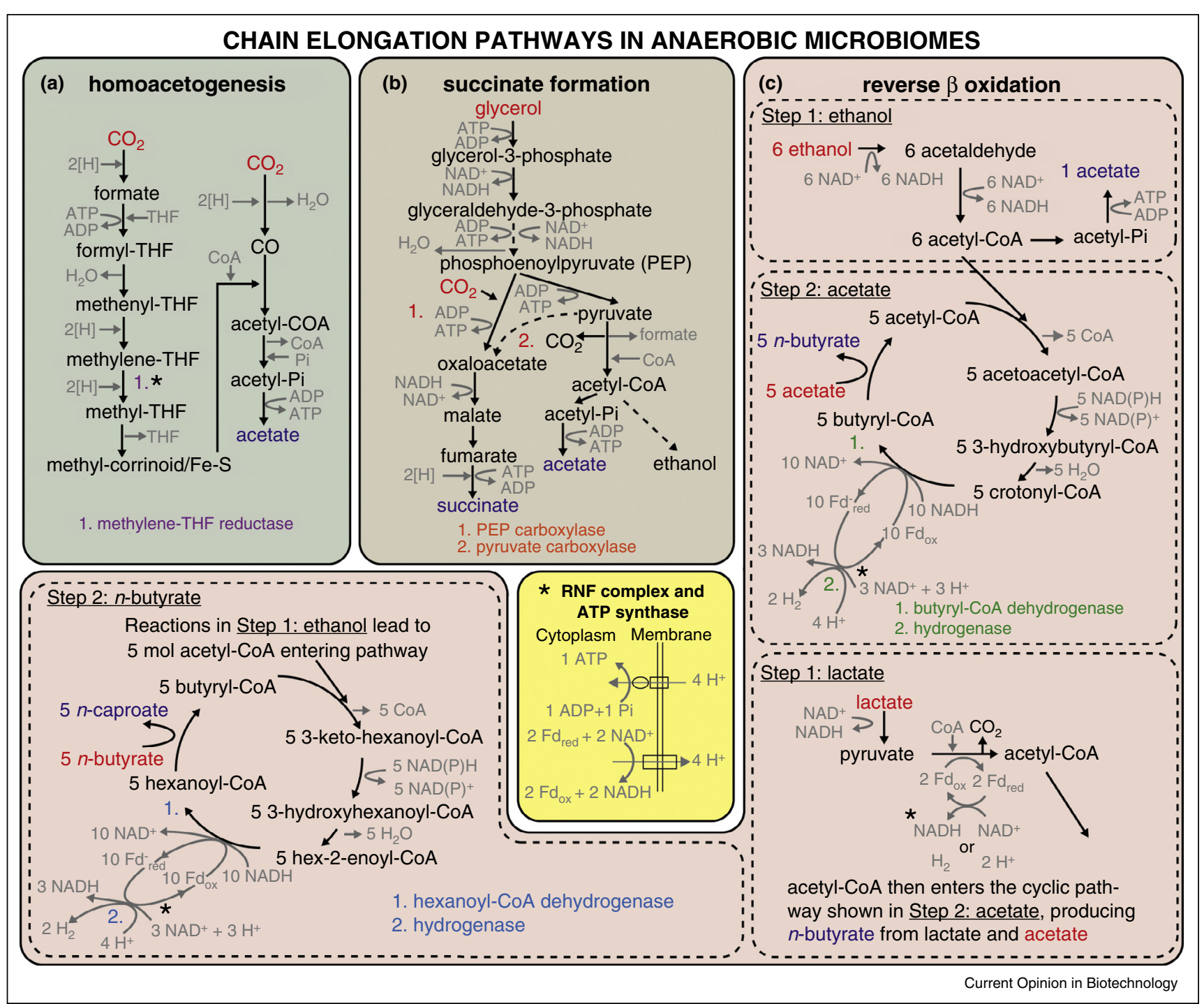

The metabolic pathways of: (a) homoacetogenesis; (b) succinate formation; and (c) reverse $\beta$ oxidation are shown. Substrates are highlighted in red, while products are highlighted in dark blue for each pathway. Key enzymes discussed in the text and the reactions they catalyze are also highlighted in the pathways. For reverse $\beta$ oxidation: ethanol as the source of reducing equivalents and energy is shown in Step 1: ethanol; reverse $\beta$ oxidation of acetate to $n$-butyrate is shown in Step 2: acetate; lactate as the source of reducing equivalents and energy is shown in Step 1: lactate; and reverse $\beta$ oxidation of $n$-butyrate to $n$-caproate is shown in Step 2: $n$-butyrate. Locations of energy recovery $\left(^{*}\right)$ are highlighted for each respective pathway, if they are known. It has been suggested that many bacteria harvest energy via the RNF complex, which is coupled with flavin-based electron bifurcation (FBEB). The starred central box $\left(^{\star}\right)$ contains an example of energy conservation via RNF complex and ATP-synthase. The RNF complex couples the oxidation of reduced ferredoxin with the reduction of $\mathrm{NAD}^{+}$to drive formation of a proton/sodium gradient across the membrane, generating ATP via ATP-synthase. Note for (c) that some of the $\mathrm{Fd}^{-}$red generated during crotonyl-CoA reduction is also used for the generation of $\mathrm{NADH}$, which is needed for reduction in the reverse $\beta$ oxidation cycle. Figure was generated with information from $[7,8,10,20,26,52,53,54]$.

elongate $\mathrm{CO}_{2}$ into acetate, which is a $\mathrm{C} 1$ to $\mathrm{C} 2$ chainelongation pathway, with $\mathrm{H}_{2}$ as an electron donor (Figure 1a, Table 1). Latif et al. [7] (this issue) reviewed this pathway in detail with updated information on energy conservation and redox homeostasis. Well-characterized homoacetogens are within the genera Clostridium and Acetobacterium [8], but this property is also found in members of many other genera such as Moorella and Sporumosa.
The overall conversion of $\mathrm{H}_{2}$ and $\mathrm{CO}_{2}$ into acetate is thermodynamically favorable at a $\mathrm{pH}$ of 7 with Gibbs free energy change values of -75 to $-95 \mathrm{~kJ} / \mathrm{mol}$ depending on temperature (Table 1). However, Kleerebezem and van Loosdrecht [9] predicted that under methanogenic conditions (low $\mathrm{H}_{2}$ partial pressure of $<10^{-2} \mathrm{kPa}$ in a reactor microbiome), a temperature exceeding $45^{\circ} \mathrm{C}$ would stop acetate generation from $\mathrm{H}_{2} / \mathrm{CO}_{2}$. Via additional 
Table 1

\begin{tabular}{|c|c|c|c|c|c|c|}
\hline Pathway & Microbe & Chain-elongation reactions & $\begin{array}{l}\text { Coupled } \\
\text { reactions }\end{array}$ & $\begin{array}{c}\Delta G_{r}^{\circ} \\
(\mathrm{kJ} / \mathrm{mol} \\
\left.\text { at } 25^{\circ} \mathrm{C}\right)\end{array}$ & $\begin{array}{c}\Delta G_{r}^{o^{\prime}} \\
(\mathrm{kJ} / \mathrm{mol} \\
\left.\text { at } 37^{\circ} \mathrm{C}\right)\end{array}$ & $\begin{array}{c}\Delta G_{r}^{\mathrm{o}^{\prime}} \\
(\mathrm{kJ} / \mathrm{mol} \\
\left.\text { at } 55^{\circ} \mathrm{C}\right)\end{array}$ \\
\hline Homoacetogenesis & C. thermoaceticum & $\begin{array}{l}4 \mathrm{H}_{2}+2 \mathrm{CO}_{2} \rightarrow \text { acetate }^{-} \\
+\mathrm{H}^{+}+2 \mathrm{H}_{2} \mathrm{O}\end{array}$ & - & -94.96 & -86.83 & -74.67 \\
\hline Succinate formation & A. succinogenes & $\begin{array}{l}\text { Glycerol }+\mathrm{CO}_{2} \rightarrow \\
\text { succinate } \\
\text { s- }+\mathrm{H}_{2} \mathrm{O}+2 \mathrm{H}^{+}\end{array}$ & - & -44.50 & -41.25 & -36.37 \\
\hline Ethanol oxidation & C. kluyveri & $\begin{array}{l}\text { Ethanol }+\mathrm{H}_{2} \mathrm{O} \rightarrow \text { acetate }^{-} \\
+\mathrm{H}^{+}+2 \mathrm{H}_{2}\end{array}$ & $\times 1$ & 10.50 & 7.54 & 4.36 \\
\hline Reverse $\beta$ oxidation & & $\begin{array}{l}\text { Ethanol }+ \text { acetate }^{-} \rightarrow \\
n \text {-butyrate } \\
+\mathrm{H}_{2} \mathrm{O}\end{array}$ & $\times 5$ & $-193.00^{a}$ & $-191.37^{\mathrm{a}}$ & $-188.33^{a}$ \\
\hline $\begin{array}{l}\text { Chain elongation of acetate and } \\
\text { ethanol to } n \text {-butyrate }\end{array}$ & & $\begin{array}{l}6 \text { ethanol }+4 \text { acetate }^{-} \\
\rightarrow 5 n \text {-butyrate } \\
+2 \mathrm{H}_{2}+4 \mathrm{H}_{2} \mathrm{O}\end{array}$ & Overall & $-182.50^{a}$ & $-183.83^{a}$ & $-183.97^{a}$ \\
\hline Ethanol oxidation & C. kluyveri & $\begin{array}{l}\text { Ethanol }+\mathrm{H}_{2} \mathrm{O} \rightarrow \\
\text { acetate }^{-}+\mathrm{H}^{+}+2 \mathrm{H}_{2}\end{array}$ & $\times 1$ & 10.50 & 7.54 & 4.36 \\
\hline Reverse $\beta$ oxidation & & $\begin{array}{l}\text { Ethanol }+n \text {-butyrate } \text { - }^{-} \rightarrow \\
n \text {-caproate } \\
-\mathrm{H}_{2} \mathrm{O}\end{array}$ & $\times 5$ & $-194.00^{\mathrm{a}}$ & $-192.49^{a}$ & $-190.22^{a}$ \\
\hline $\begin{array}{l}\text { Chain elongation of } n \text {-butyrate } \\
\text { and ethanol to } n \text {-caproate }\end{array}$ & & $\begin{array}{l}6 \text { ethanol }+5 n \text {-butyrate } \\
\rightarrow \text { acetate }^{-}+5 n \text {-caproate } \\
+\mathrm{H}^{+}+2 \mathrm{H}_{2}+4 \mathrm{H}_{2} \mathrm{O}\end{array}$ & Overall & $-183.50^{a}$ & $-184.95^{\mathrm{a}}$ & $-185.86^{a}$ \\
\hline $\begin{array}{l}\text { Chain elongation of acetate and } \\
\text { lactate to } n \text {-butyrate } \\
\text { (via reverse } \beta \text { oxidation) }\end{array}$ & M. elsdenii & $\begin{array}{l}\text { Lactate }^{-}+\text {acetate }^{-} \\
+\mathrm{H}^{+} \rightarrow n \text {-butyrate } \\
+\mathrm{CO}_{2}+\mathrm{H}_{2} \mathrm{O}\end{array}$ & Overall & -57.74 & -59.43 & -61.97 \\
\hline
\end{tabular}

a The unit is $\mathrm{kJ} / 5 \mathrm{~mol}$ of product.

thermodynamic calculations, Gonzalez-Cabaleiro et al. $\left[10^{\bullet \bullet}\right]$ confirmed that energy investment is required in the $\mathrm{CO}_{2}$ to $\mathrm{CO}$ reduction step of the homoacetogenesis pathway (biological standard conditions $\left[\mathrm{pH} 7 ; 25^{\circ} \mathrm{C}\right]$ ). They also predicted that methylene THF reductase is the enzyme most probably coupled with proton translocation to provide energy recovery in the pathway $\left[10^{\bullet \bullet}\right]$. Acetogens (e.g. A. woodii and C. ljungdahlii) link methylene THF reductase to flavin-based electron bifurcation $(\mathrm{FBEB})$ and the RNF complex (NADH:ferredoxin oxidoreductase) to conserve energy (* in Figure 1) [7].

When the $\mathrm{H}_{2}$ partial pressure declines in the system, a decrease occurs in the total energy that is available for the pathway. Eventually, at very low $\mathrm{H}_{2}$ partial pressures of $<10^{-2} \mathrm{kPa}$, no net energy can be harvested from proton translocation, rendering this pathway unfeasible $\left[10^{\circ}\right]$. Thus, a thermodynamic bottleneck may exist within the microbiome at low $\mathrm{H}_{2}$ partial pressures, and thus $\mathrm{H}_{2}$ conversion via methanogenic archaeal and sulfate-reducing bacterial activity must be limited to achieve chain elongation. From chemostat experiments it was hypothesized that only a narrow range of growth rates are feasible for homoacetogenesis [11]. In addition, the homoacetogenesis pathway is reversible at very low $\mathrm{H}_{2}$ partial pressures in microbiomes, and calculations have indicated that the energy coupling sites are the same in both directions [10*0. Finally, Ni et al. [12] estimated that hydrogenotrophic methanogens outcompete homoacetogens within microbiomes at low $\mathrm{H}_{2}$ partial pressures, while this is vice versa at high $\mathrm{H}_{2}$ partial pressures (e.g. from fermentation). The conversion of $\mathrm{H}_{2}$ and $\mathrm{CO}_{2}$ into acetate is more energetically favorable at higher $\mathrm{H}_{2}$ partial pressures, indicating that pressurized bioreactors may be attractive [13].

Currently, $\sim 10$ million tons of acetate are produced annually, mainly via petrochemical methods [8]. The Wood-Ljungdahl pathway through acetogenic activity in the microbiome could fix the $\mathrm{CO}_{2}$ that is commonly lost during industrial fermentations [14] with $\mathrm{H}_{2}$ as the electron donor via electrolysis of surplus, renewable electric power. The rates of acetate production for homoacetogens in pure-culture fermentations have been favorable with production rates of $0.3-0.4 \mathrm{~g}$ final product $\mathrm{L}^{-1} \mathrm{~h}^{-1}$ $[13,15]$. This rate is not limited by the microbial activity but by the $\mathrm{H}_{2}$ gas transfer into solution [16]. Considerably lower production rates of $1 \times 10^{-2}-6 \times 10^{-3} \mathrm{~g} \mathrm{~L}^{-1} \mathrm{~h}^{-1}$ from homoacetogenic activity in microbiomes from supplied $\mathrm{H}_{2}$ and $\mathrm{CO}_{2}$ have been found compared to pure culture fermentations $[12,17]$.

\section{Succinate formation (b)}

Succinate is a dicarboxylate that can be produced by several very different microbial pathways. Succinate is a key intermediate in the Krebs cycle (citric acid cycle) to 
degrade organic compounds completely to $\mathrm{CO}_{2}$. It is also an intermediate of anaerobic bacteria that form or degrade propionate. Here, succinate production is discussed because of the ability of specific anaerobic bacteria to chain elongate the waste product glycerol (C3) with $\mathrm{CO}_{2}$ (C1) into succinate (C4), which is a $\mathrm{C} 1$ chain-elongation pathway (Figure 1b, Table 1). This $\mathrm{CO}_{2}$ fixation pathway, therefore, includes a carboxylation reaction, such as via the Wood-Ljungdahl pathway or the Arnon-Buchanan cycle (reverse citric acid cycle) in strict anaerobic bacteria, which results in the elongation of the chain length of organic molecules [18]. Carboxylation reactions even occur in bacteria that are heterotrophic and produce net $\mathrm{CO}_{2}$. To our knowledge, succinate fermentation is the only fermentation pathway in which net $\mathrm{CO}_{2}$ is consumed when sugars are the substrates (including glycerol as a sugar backbone). This is due to synthesis of oxaloacetate by carboxylation of: 1 . pyruvate with pyruvate carboxylase; or 2 phosphoenoylpyruvate (PEP) with PEP carboxylase (Figure 1b).

Actinobacillus succinogenes and Basfia succiniciproducens are bovine ruminal species that are able to ferment glycerol to succinate with the former being considered as a promising bacterium in respect to industrial succinate production [19-21]. The elongation of glycerol and $\mathrm{CO}_{2}$ into succinate is thermodynamically favorable under standard conditions with a Gibbs free energy change value of $-40 \mathrm{~kJ} /$ mol (Table 1). Succinate production is a fermentation pathway in which external $\mathrm{CO}_{2}$ is required to sustain redox and carbon balances, especially when the bacteria have a limited capacity to dispose off excess reducing equivalents by, for example, the formation of ethanol, lactate, or hydrogen. Zou et al. [21] has already observed that increasing the dissolved $\mathrm{CO}_{2}$ concentration has a positive effect on rates for pure cultures. In-depth thermodynamic calculations are necessary to investigate whether thermodynamic bottlenecks exist for the elongation of glycerol in microbiomes.

Succinate is an important additive in the food and pharmaceutical industry. In addition, it is a platform chemical for bulk organic synthesis, with a total production of more than 20,000 to 30,000 tons annually via petrochemical methods [22]. The volume of generated glycerol, which is a side product of biodiesel production, is large enough to cover all potential demand for succinate if this microbial fermentation pathway becomes optimized. Already, relatively high succinate production rates from glucose and $\mathrm{CO}_{2}$ with pure cultures of $A$. succinogenes of $0.86 \mathrm{~g}$ final product $\mathrm{L}^{-1} \mathrm{~h}^{-1}$ have been observed after increasing the dissolved $\mathrm{CO}_{2}$ concentration by adding $\mathrm{MgCO}_{3}$ as a $\mathrm{CO}_{2}$ source at a $\mathrm{CO}_{2}$ partial pressure of $101.33 \mathrm{kPa}$ (i.e. $100 \% \mathrm{CO}_{2}$ gas). However, because of its isolation from a nutrient-rich rumen environment, the nutrient requirements for this pure culture are too high for an economically viable system. We already know that a glycerol-to-succinate-converting bacterium exists in the nutrient-poor environment of a reactor microbiome, which treats sludge. However, research is required to select for such reactor microbiome to perform this pathway at sufficiently high rates [23].

\section{Reverse $\beta$ oxidation (c)}

The $\beta$ oxidation pathway is a reversible metabolic pathway that can perform either the oxidation or reduction reaction depending on specific certain anaerobic conditions $\left[10^{\circ}\right]$. Because of the abundance of $\beta$ oxidation in anaerobic reactor microbiomes, the metabolic trait to operate in the reverse is likely already present when the environmental conditions become favorable. The first required environmental condition is the presence of energy-rich, reduced compounds, such as ethanol and lactate, to provide energy, reducing equivalents, and acetyl-CoA via step-1 microbial pathways (Figure 1c; Step 1: ethanol and Step 1: lactate). This is followed by the cyclic, step-2 reverse $\beta$ oxidation pathways (Figure 1c; Step 2: acetate and Step 2: n-butyrate), and both steps together form the chain elongation of interest (Table 1). In the reactor microbiome, a high enough $\mathrm{H}_{2}$ partial pressure is the second environmental condition that should be met to prevent the oxidation, and thus removal, of short-chain and medium-chain carboxylates [24].

For every 5 molecules of ethanol that is used for C2 elongation, 1 molecule of ethanol is oxidized into acetate (Table 1) to provide metabolic energy (ATP) via substrate level phosphorylation. The conversion of ethanol also provides reducing equivalents (NADH) for the reverse $\beta$ oxidation cycle (Figure 1c; Step 1: ethanol). Lactate conversion has also been described to generate the necessary acetyl-CoA to provide the two carbon atoms for the acetate to $n$-butyrate elongation via reverse $\beta$ oxidation (Figure 1c; Step 1: lactate) $\left[10^{\bullet \bullet}, 25,26\right]$ with ATP generation from the conversion of pyruvate into acetyl-CoA (likely by oxidation of ferredoxin by a membrane-bound RNF complex) and NADH formation from the conversion of lactate into pyruvate [26] (Figure 1c).

The reverse $\beta$ oxidation pathway is a cyclic process and adds an acetyl-CoA molecule, which is derived from ethanol or lactate (step 1), to a carboxylate, elongating its carbon chain length with $\mathrm{C} 2$ at a time (i.e. acetate [C2] to $n$-butyrate [C4] (Figure 1c; Step 2: acetate), $n$-butyrate [C4] to $n$-caproate [C6] (Figure 1c; Step 2: $n$-butyrate), $n$-caproate [C6] to $n$-caprylate [C8], propionate [C3] to $n$-valerate [C5], among others) $\left[3^{\bullet}, 27^{\bullet \bullet}, 28\right]$. Calculations and experimental work showed that energy harvesting via proton translocation (including the use of the RNF complex [* in Figure 1c]) occurs in the pathway where crotonyl-CoA is reduced to butyryl-CoA with butyrylCoA dehydrogenase or hex-2-enoyl-CoA is reduced to hexanoyl-CoA with hexanoyl-CoA dehydrogenase $\left[10^{\bullet \bullet}, 25\right]$. Numerous bacteria in the microbiome have 
all the necessary enzymes to perform the reverse $\beta$ oxidation pathway, with Clostridium kluyveri being the best-known microbe that can perform this both in pure and open cultures, including the ethanol oxidation pathway to obtain energy (Step 1: ethanol) $\left[1,3^{\bullet}\right]$.

The combined pathways of ethanol oxidation and reverse $\beta$ oxidation that form chain elongation are thermodynamically feasible at a $\mathrm{pH}$ of 7 with a Gibbs free energy change value of $\sim-185 \mathrm{~kJ} / 5 \mathrm{~mol}$ at temperatures that range from $25^{\circ} \mathrm{C}$ to $55^{\circ} \mathrm{C}$ for both $n$-butyrate and $n$-caproate production (Table 1). Further calculations showed that under a range of ethanol concentrations no thermodynamic bottlenecks exist for acetate elongation to $n$-butyrate with ethanol as the electron donor $(\mathrm{pH} \mathrm{7}$; $\left.25^{\circ} \mathrm{C}\right)\left[10^{\circ \bullet}\right]$. However, the chain elongation pathway (i.e. the combined ethanol oxidation and reverse $\beta$ oxidation pathways for $n$-caproate production) did not occur at $55^{\circ} \mathrm{C}$ in bioreactors, while it did occur at $30^{\circ} \mathrm{C}$. Therefore, chain elongation may be limited by a thermodynamic bottleneck or end product toxicity at the higher temperatures [24]. For the combined pathway that elongates acetate and lactate into $n$-butyrate, we calculated a Gibbs free energy change value of $\sim-60 \mathrm{~kJ} / \mathrm{mol}$ at temperatures that range from $25^{\circ} \mathrm{C}$ to $55^{\circ} \mathrm{C}$ (Table 1 ). Megasphaera elsdenii has been of interest in recent studies regarding this combined pathway [26,29].

When $\mathrm{H}_{2}$ was used as the electron donor instead of ethanol in thermodynamic calculations $\left(\right.$ at $\mathrm{H}_{2}$ partial pressures of $1 \times 10^{-3}, 1 \times 10^{-1}, 10,50$, and $100 \mathrm{kPa}$ ), a thermodynamic bottleneck was found due the highly endergonic two acetyl-CoA condensation reaction, requiring unfeasibly low acetoacetyl-CoA concentrations $\left[10^{\circ \bullet}\right]$. We, therefore, assume that the direct generation of $n$ caproate from $\mathrm{H}_{2}$ and $\mathrm{CO}_{2}$ cannot occur even at high $\mathrm{H}_{2}$ partial pressures. This may explain why feeding only $\mathrm{H}_{2}$ and $\mathrm{CO}_{2}$ to a microbiome with the goal to produce medium-chain carboxylates, such as $n$-caproate, resulted in very low volumetric production rates of $\sim 1 \times 10^{-3} \mathrm{~g}$ $n$-caproate $\mathrm{L}^{-1} \mathrm{~h}^{-1}$ [17]. The sluggish indirect generation of $n$-caproate can be explained via sequential pathways of homoacetogenesis, acetate reduction to ethanol [30], and the combined ethanol oxidation/reverse $\beta$ oxidation. This is a slow sequential process because of the sluggish kinetics of acetate reduction in reactor microbiomes [30]. Acetate reduction into ethanol is much faster with a high-rate homoacetogenic bioprocess, such as synthesis gas (syngas: a mixture of primarily $\mathrm{CO}, \mathrm{H}_{2}$ and $\mathrm{CO}_{2}$ ) fermentation with pure cultures [15]. The effluent of syngas fermentation can then be fed into a high-rate chain elongation bioprocess in reactor microbiomes to considerably increase the overall rate of $\mathrm{H}_{2}$ and $\mathrm{CO}_{2}$ conversion into $n$-caproate $\left[31^{\circ}\right]$.

Currently, $n$-caproate is commercially produced via various petrochemical methods. When microbiomes can generate medium-chain carboxylates economically, a market will likely develop to use $n$-caproate as a sustainable platform chemical: 1 . directly as animal feed, green antimicrobials, or corrosion inhibitors [1,32,33]; or 2 . indirectly by conversion with organic chemistry into biofuels such as biodiesel or jet fuels [34]. Research has already shown relatively high volumetric rates and specificities for production of medium-chain carboxylates in microbiomes, and two different approaches have emerged. One approach has been to use procured acetate and ethanol as substrates and to operate bioreactors at a $\mathrm{pH}$ of 7 without in-line product extraction. This approach has achieved the highest volumetric production rates of $2.2 \mathrm{~g} n$-caproate $\mathrm{L}^{-1} \mathrm{~h}^{-1}$ to date $\left[27^{\circ \bullet}, 32,35^{\circ}\right]$. The other approach has been to use realistic substrates, such as ethanol beer or syngas fermentation effluent, and to operate bioreactors at a lower $\mathrm{pH}$ of $\sim 5.5$ to: 1 . prevent acetoclastic methanogenic activity; and 2. to generate a $\mathrm{pH}$ gradient to extract the undissociated $n$-caproic acid from the broth via in-line liquid/liquid extraction $\left[3^{\bullet}, 31^{\circ}\right]$. This has resulted in an excellent selectivity of $\sim 80 \%$ even though the substrate was complex $\left[3^{\circ}\right]$. Due to the toxic nature of undissociated $n$-caproic acid at a lower $\mathrm{pH}$ value of 5.5 [33,36], $n$-caproate must be extracted out of the broth. The relatively low maximum solubility of $n$-caproic acid is advantageous for in-line extraction, especially when compared to the complete miscible nature of ethanol. Therefore, $n$-caproate production/extraction is perceived as a possible alternative to energy-intensive ethanol distillation when the product toxicity of $n$-caproic acid can be managed $\left[3^{\circ}, 31^{\circ}\right]$.

\section{Technologies}

To maximize the selectivity of the elongated products, technology on the periphery of the fermentors may be necessary to serve three different purposes: 1 . to remove or deliver electrons, and therefore to aid fermentation, by implementing electrodes and power sources; 2. to separate the products by in-line extraction technology; or 3 . to convert fermentation products further with post-processing technologies, possibly to aid separation.

\section{Electrodes}

Microbial electrocatalysis with power-source-controlled electrodes that are placed in anaerobic bioreactors (fermentors) can be utilized as an oxidative or reductive driver for microbial production processes [37,38]. The use of electric power is attractive because it can be produced sustainably without arable land requirements [39]. An oxidative driver involves an anode as an electron sink to discharge reducing equivalents via the electrical circuit. Currently, industrial fermentations often require oxygen addition to restore the metabolic redox balance, but the use of electrodes may circumvent this practice. An early proof-of-concept study without external mediators was performed with genetically engineered Shewanella oneidensis MR-1 to discharge excess electrons during the 
conversion of glycerol to ethanol via glycolysis [40]. A reductive driver involves a cathode as an electron source, and several reactor microbiomes (biocathodes) have already achieved the production of acetate through homoacetogenesis at rates of $0.04 \mathrm{~g} \mathrm{~L}^{-1} \mathrm{~h}^{-1}\left[41^{\bullet \bullet}, 42\right]$, which is higher than the rate of homoacetogenesis in microbiomes as described earlier. Homoacetogenesis with electrodes is one route of microbial electrosynthesis. In addition, cathode utilization within a bioreactor with glycerol fermentation enhanced production of alcohols and indirectly led to reverse $\beta$ oxidation to produce $n$ valerate from propionate [43]. In two other studies with reactor microbiomes, the reverse $\beta$ oxidation pathway was observed with biocathodes but without the supply of fermentable substrates or ethanol, albeit at low production rates due to the requirement of acetate to ethanol reduction $[44,45]$.

\section{Extraction}

Operating conditions with lower $\mathrm{pH}$ values result in toxic environments when short-chain or medium-chain carboxylates are being generated [33], and therefore a need was identified to continuously extract the product from the fermentation broth [24]. Four separation methods will be briefly discussed here: 1 . liquid-liquid extraction; 2. crystallization; 3 . ion exchange; and 4. electrodialysis. With liquid-liquid extraction, a solvent is used to extract the desired compound from the fermentation broth [46]. The compound can then be back-extracted into an aqueous solution via a $\mathrm{pH}$ gradient, and this was performed with fermentation broth from a reactor microbiome $\left[3^{\bullet}, 24\right]$. This technology will favor the extraction of more hydrophobic compounds, such as undissociated $n$-caproic acid (i.e. $n$-caproic acid has a solubility of $10.19 \mathrm{~g} / \mathrm{L}$ in water) compared to undissociated $n$-butyric acid (about $100 \mathrm{~g} / \mathrm{L}$ in water), and this will select for the reactor microbiome to promote chain elongation $\left[3^{\circ}\right]$. Crystallization has been integrated with reactor microbiome technology to extract a mixture of short-chain carboxylates as part of the MixAlco process [47]. In addition, crystallization of succinate was discussed in detail, but problems of sluggish extraction were noted due to its relatively high maximum solubility, which can be possibly circumvented by direct conversion into other products that are easier to extract [22]. Ion exchange resins rely on a stoichiometric process in which certain compounds, such as carboxylates, are adsorbed to the resin and removed from the fermentation broth [46]. Electrodialysis is a process in which ion exchange membranes are used to selectively extract ions from one solution to another based on an electrical potential difference [46]. This technology has been applied to the separation of acetic acid from acetaldehyde wastewater [48] and the recovery of succinate [46]. More work is necessary to specifically extract elongated products from reactor microbiomes and undoubtedly new technology will be developed [46].

\section{Conversion}

Immediate conversion of the elongation products may be implemented to: 1 . increase product value; 2 . convert carboxylates into fuel chemicals; and/or 3. aid in product separation. Many biochemical, electrochemical, and thermochemical conversions are possible to upgrade carboxylates [22,34,49]. Conversion of carboxylates into fuelgrade chemicals can be achieved by reducing them to their corresponding alcohols. The latter are less corrosive, and have better combustion properties. Reduction of a carboxyl into an alcohol function requires energy and reducing equivalents, since the alcohol is more reduced and its combustion can release more free energy than that of the carboxylate. Syngas in a biochemical reaction can provide energy and reducing equivalents, which resulted in highly efficient conversions for several carboxylates including $n$-caproate to $n$-hexanol [50]. In another study, the conversion of carboxylates, such as $n$-caproate, into a C6 alkene platform was described via metal catalytic conversions to generate jet fuels [34]. The conversion of carboxylates can also decrease the maximum solubility, and therefore improve product separation. This concept was discussed in a review where the conversion of succinate to solvents, such as pyrrolidones, or succinic esters or succinate amines was highlighted [22].

\section{Conclusions}

Even though many older reports exists that describe the presence of chain-elongation reactions in anaerobic reactor microbiomes, a new concept has emerged that has its primary goal of producing elongated carboxylates with these systems. Besides the three pathways that we have described in this review, it is foreseeable that other pathways, such as the elongation of acetate (C2) and propanol (C3) into $n$-valerate (C5) [29], can be utilized in reactor microbiomes to produce elongated carboxylates. For each of these pathways, whether they have already been described or not, it is pertinent that the microbiome is shaped to primarily enrich for the enzymatic reactions of interest. Many questions exist on how to shape the microbiome and, if successful, whether the system is stable and resilient to withstand operating upsets that may occur during industrial processing (similar to methanogenic microbiomes). The other areas that need study are the extraction and/or conversion technologies, which when used in line with the fermentation system, can be used as large drivers. In fact, for certain chain-elongating pathways, in-line extraction may be a prerequisite to shape the reactor microbiome to obtain a high production rate and selectivity. Another driver may be the use of electrodes in large-scale fermenters, but further scale-up work is necessary before practical application will become important.

\section{Acknowledgements}

The authors thank Wolfgang Buckel (MPI Marburg) for assistance with Figure 1. C.M.S. and L.T.A. were supported by the U. S. Army Research 
Laboratory and the U. S. Army Research Office under contract/grant number W911NF-12-1-0555. H.R. was supported for this work by the Cornell University Agricultural Experiment Station federal formula funds, Project No. NYC-123452 received from the National Institutes for Food and Agriculture (NIFA), U.S. Department of Agriculture. K.R. was supported by the European Research Council Starter Grant Electrotalk and the Multidisciplinary Research Partnership Ghent Bio-Economy. A.J.M.S. was supported by the Chemical Sciences division of the Netherlands Science Foundation (CW-TOP 700.55.343) and the European Research Council (ERC grant 323009).

\section{References and recommended reading}

Papers of particular interest, published within the period of review, have been highlighted as:

- of special interest

•• of outstanding interest

1. Agler MT, Wrenn BA, Zinder SH, Angenent LT: Waste to bioproduct conversion with undefined mixed cultures: the carboxylate platform. Trends Biotechnol 2011, 29:70-78.

2. Zaks DPM, Winchester N, Kucharik CJ, Barford CC, Paltsev S, Reilly JM: Contribution of anaerobic digesters to emissions mitigation and electricity generation under U.S. climate policy. Environ Sci Technol 2011, 45:6735-6742.

3. Agler MT, Spirito CM, Usack JG, Werner JJ, Angenent LT: Chain

- elongation with reactor microbiomes: upgrading dilute ethanol to medium-chain carboxylates. Energy Environ Sci 2012, 5:8189-8192.

First study to extract elongated product from a reactor microbiome and also first study that uses a real substrate solution to show that elongation could be an alternative to ethanol distillation.

4. Werner JJ, Knights D, Garcia ML, Scalfone NB, Smith S,

- Yarasheski K, Cummings TA, Beers AR, Knight R, Angenent LT: Bacterial community structures are unique and resilient in fullscale bioenergy systems. Proc Natl Acad Sci U S A 2011, 108:4158-4163.

One of the first studies to use constrained ordination to statistically link the structure of the reactor microbiome with 16S rRNA gene sequencing to function of the anaerobic fermentor. The study also shows that microbiomes are resilient to operating upsets.

5. Marshall CW, LaBelle EV, May HD: Production of fuels and chemicals from waste by microbiomes. Curr Opin Biotechnol 2013, 24:391-397.

6. Weiland P: Biogas production: current state and perspectives. Appl Microbiol Biotechnol 2010, 85:849-860.

7. Latif H, Zeidan AA, Nielsen AT, Zengler K: Trash to treasure: syngas fermentation for the production of biofuels and commodity chemicals. Curr Opin Biotechnol 2014, 27:79-87 (this issue).

8. Schiel-Bengelsdorf B, Dürre P: Pathway engineering and synthetic biology using acetogens. FEBS Lett 2012, 586 2191-2198.

9. Kleerebezem R, Van Loosdrecht MCM: A generalized method for thermodynamic state analysis of environmental systems. Crit Rev Env Sci Technol 2010, 40:1-54.

10. Gonzalez-Cabaleiro R, Lema JM, Rodriguez J, Kleerebezem R:

-. Linking thermodynamics and kinetics to assess pathway reversibility in anaerobic bioprocesses. Energy Environ Sci 2013, 6:3780-3789.

In-depth thermodynamic calculations for several chain-elongation reactions. The authors provide the necessary thermodynamic information to predict what chain elogangation reactions are feasible.

11. de Kok S, Meijer J, van Loosdrecht MCM, Kleerebezem R: Impact of dissolved hydrogen partial pressure on mixed culture fermentations. Appl Microbiol Biotechnol 2013, 97:2617-2625.

12. Ni B-J, Liu H, Nie Y-Q, Zeng RJ, Du G-C, Chen J, Yu H-Q: Coupling glucose fermentation and homoacetogenesis for elevated acetate production: experimental and mathematical approaches. Biotechnol Bioeng 2011, 108:345-353.
13. Demler M, Weuster-Botz D: Reaction engineering analysis of hydrogenotrophic production of acetic acid by Acetobacterium woodii. Biotechnol Bioeng 2011, 108:470-474.

14. Tracy BP, Jones SW, Fast AG, Indurthi DC, Papoutsakis ET: Clostridia: the importance of their exceptional substrate and metabolite diversity for biofuel and biorefinery applications. Curr Opin Biotechnol 2012, 23:364-381.

15. Richter H, Martin ME, Angenent LT: A two-stage continuous fermentation system for conversion of syngas into ethanol. Energies 2013, 6:3987-4000.

16. Munasinghe PC, Khanal SK: Syngas fermentation to biofuel: evaluation of carbon monoxide mass transfer coefficient (kla) in different reactor configurations. Biotechnol Prog 2010, 26:1616-1621.

17. Zhang F, Ding J, Zhang Y, Chen M, Ding Z-W, van Loosdrecht MCM, Zeng RJ: Fatty acids production from hydrogen and carbon dioxide by mixed culture in the membrane biofilm reactor. Water Res 2013, 47:6122-6129.

18. Fuchs G: Alternative pathways of carbon dioxide fixation: insights into the early evolution of life? Annu Rev Microbiol $2011,65: 631-658$

19. McKinlay J, Laivenieks M, Schindler B, McKinlay A, Siddaramappa S, Challacombe J, Lowry S, Clum A, Lapidus A, Burkhart $\mathrm{K}$ et al.: A genomic perspective on the potential of Actinobacillus succinogenes for industrial succinate production. BMC Genomics 2010, 11:680.

20. Zheng $P$, Zhang $K$, Yan Q, Xu Y, Sun Z: Enhanced succinic acid production by Actinobacillus succinogenes after genome shuffling. J Ind Microbiol Biotechnol 2013, 40:831-840.

21. Zou W, Zhu L-W, Li H-M, Tang Y-J: Significance of $\mathrm{CO}_{2}$ donor on the production of succinic acid by Actinobacillus succinogenes ATCC 55618. Microb Cell Fact 2011, 10:87-97.

22. Cukalovic A, Stevens CV: Feasibility of production methods for succinic acid derivatives: a marriage of renewable resources and chemical technology. Biofuels Bioprod Biorefining 2008, 2.505-529.

23. Temudo MF, Poldermans R, Kleerebezem R, van Loosdrecht MCM: Glycerol fermentation by (open) mixed cultures: a chemostat study. Biotechnol Bioeng 2008, 100 1088-1098.

24. Agler MT, Spirito CM, Usack JG, Werner JJ, Angenent LT: Development of a highly specific and productive process for $\mathrm{n}$-caproic acid production: applying lessons from methanogenic microbiomes. Water Sci Technol 2014, 69:62-68.

25. Muñoz-Tamayo R, Laroche B, Walter É, Doré J, Duncan SH, Flint $\mathrm{HJ}$, Leclerc M: Kinetic modelling of lactate utilization and butyrate production by key human colonic bacterial species. FEMS Microbiol Ecol 2011, 76:615-624.

26. Prabhu R, Altman E, Eiteman MA: Lactate and acrylate metabolism by Megasphaera elsdenii under batch and steadystate conditions. Appl Environ Microbiol 2012, 78:8564-8570.

27. Steinbusch KJ, Hamelers HVM, Plugge CM, Buisman CJN:

- Biological formation of caproate and caprylate from acetate: fuel and chemicals from low grade biomass. Energy Environ Sci 2011, 4:216-224.

First study with the specific goal to produce medium-chain carboxylates with reactor microbiomes.

28. Grootscholten TIM, Steinbusch KJJ, Hamelers HVM Buisman CJN: High rate heptanoate production from propionate and ethanol using chain elongation. Bioresour Technol 2013, 136:715-718.

29. Weimer PJ, Moen GN: Quantitative analysis of growth and volatile fatty acid production by the anaerobic ruminal bacterium Megasphaera elsdenii T81. App/ Microbiol Biotechnol 2013, 97:4075-4081.

30. Steinbusch KJ, Hamelers HV, Buisman CJ: Alcohol production through volatile fatty acids reduction with hydrogen as electron donor by mixed cultures. Water Res 2008, 42 4059-4066. 
31. Vasudevan D, Richter $\mathrm{H}$, Angenent LT: Upgrading dilute ethanol - from syngas fermentation to $\mathrm{n}$-caproate with reactor microbiomes. Bioresour Technol 2014, 151:378-382.

Second study that uses a real substrate solution to show that elongation could be an alternative to ethanol distillation.

32. Grootscholten TIM, Steinbusch KJJ, Hamelers HVM, Buisman CJN: Improving medium chain fatty acid productivity using chain elongation by reducing the hydraulic retention time in an upflow anaerobic filter. Bioresour Technol 2013 136:735-738.

33. Kim SA, Rhee MS: Marked synergistic bactericidal effects and mode of action of medium-chain fatty acids in combination with organic acids against Escherichia coli O157:H7. Appl Environ Microbiol 2013, 79:6552-6560.

34. Harvey BG, Meylemans HA: 1-Hexene: a renewable $\mathbf{C 6}$ platform for full-performance jet and diesel fuels. Green Chem 2013 http://dx.doi.org/10.1039/c3gc41554f.

35. Grootscholten TIM, Steinbusch KJJ, Hamelers HVM,

- Buisman CJN: Chain elongation of acetate and ethanol in an upflow anaerobic filter for high rate MCFA production. Bioresour Technol 2013, 135:440-445.

Study with highest chain-elongation rates reported in the literature with reactor microbiomes. This work also indicates that $n$-caproate production rates are competitive with methane production rates in high-rate anaerobic wastewater treatment systems.

36. Butkus MA, Hughes KT, Bowman DD, Liotta JL, Jenkins MB, Labare MP: Inactivation of Ascaris suum by short-chain fatty acids. Appl Environ Microbiol 2011, 77:363-366.

37. Rabaey K, Rozendal RA: Microbial electrosynthesis revisiting the electrical route for microbial production. Nat Rev Microbiol 2010, 8:706-716.

38. Angenent LT, Rosenbaum MA: Microbial electrocatalysis to guide biofuel and biochemical bioprocessing. Biofuels 2013, 4:131-134.

39. Rabaey K, Girguis P, Nielsen LK: Metabolic and practical considerations on microbial electrosynthesis. Curr Opin Biotechnol 2011, 22:371-377.

40. Flynn JM, Ross DE, Hunt KA, Bond DR, Gralnick JA: Enabling unbalanced fermentations by using engineered electrodeinterfaced bacteria. mBio 2010, 1:00110-0190.

41. Marshall CW, Ross DE, Fichot EB, Norman RS, May HD:

- Electrosynthesis of commodity chemicals by an autotrophic microbial community. Appl Environ Microbiol 2012, 78:84128420

Landmark study that validates that reactor microbiomes at the cathode of bioelectrochemical systems could be utilized to produce chemicals at promising rates.

42. Marshall CW, Ross DE, Fichot EB, Norman RS, May HD: Longterm operation of microbial electrosynthesis systems improves acetate production by autotrophic microbiomes. Environ Sci Technol 2013, 47:6023-6029.
43. Dennis PG, Harnisch F, Yeoh YK, Tyson GW, Rabaey K: Dynamics of cathode-associated microbial communities and metabolite profiles in a glycerol-fed bioelectrochemical system. Appl Environ Microbiol 2013, 79:4008-4014.

44. Van Eerten-Jansen MCAA, Ter Heijne A, Grootscholten TIM, Steinbusch KJJ, Sleutels THJA, Hamelers HVM, Buisman CJN: Bioelectrochemical production of caproate and caprylate from acetate by mixed cultures. ACS Sustain Chem Eng 2013, 1:513-518.

45. Sharma M, Aryal N, Sarma PM, Vanbroekhoven K, Lal B, Benetton XD, Pant D: Bioelectrocatalyzed reduction of acetic and butyric acids via direct electron transfer using a mixed culture of sulfate-reducers drives electrosynthesis of alcohols and acetone. Chem Comm 2013, 49:6495-6497.

46. Huang H-J, Ramaswamy S: Overview of biomass conversion processes and separation and purification technologies in biorefineries. Separation and Purification Technologies in Biorefineries. John Wiley \& Sons, Ltd.; 2013:. pp. 1-36.

47. Forrest AK, Hernandez J, Holtzapple MT: Effects of temperature and pretreatment conditions on mixed-acid fermentation of water hyacinths using a mixed culture of thermophilic microorganisms. Bioresour Technol 2010 101:7510-7515.

48. Zhang X, Li C, Wang Y, Luo J, Xu T: Recovery of acetic acid from simulated acetaldehyde wastewaters: bipolar membrane electrodialysis processes and membrane selection. J Membr Sci 2011, 379:184-190.

49. Röttig A, Wenning L, Bröker D, Steinbüchel A: Fatty acid alkyl esters: perspectives for production of alternative biofuels. Appl Microbiol Biotechnol 2010, 85:1713-1733.

50. Perez JM, Richter H, Loftus SE, Angenent LT: Biocatalytic reduction of short-chain carboxylic acids into their corresponding alcohols with syngas fermentation. Biotechnol Bioeng 2013, 110:1066-1077.

51. Haynes WM: CRC Handbook of Chemistry and Physics Online. LLC: Taylor and Francis Group; 2013, .. 94 $4^{\text {th }}$ edition.

52. Seedorf $\mathrm{H}$, Fricke WF Veith $\mathrm{B}$, Brüggemann $\mathrm{H}$, Liesegang $\mathrm{H}$, Strittmatter A, Miethke M, Buckel W, Hinderberger J, Li F et al.: The genome of Clostridium kluyveri, a strict anaerobe with unique metabolic features. Proc Natl Acad Sci U S A 2008 , 105:2128-2133.

53. Li C, Lesnik K, Liu H: Microbial conversion of waste glycerol from biodiesel production into value-added products. Energies 2013, 6:4739-4768.

54. Chowdhury NP, Mowafy AM, Demmer JK, Upadhyay V, Koelzer S, Jayamanini E, Kahnt J, Hornung M, Demmer U, Ermler U et al:: Studies on the mechanism of electron bifurcation catalyzed by electron transferring flavoprotein (Etf) and butyryl-coa dehydrogenase (Bcd) of Acidaminococcus fermentans. J Biol Chem 2014. In press. 